\title{
One Phase Soil Bio-Cementation with EICP-Soil Mixing
}

\author{
Haider Rohy', Mohamed Arab,2, Waleed Zeiada1, Maher Omar', Abdullah Almajed ${ }^{3}$, Ali Tahmaz ${ }^{1}$ \\ ${ }^{1}$ Department of Civil and Environmental Engineering, College of Engineering, University of Sharjah \\ P. O. Box 27272 Sharjah, Sharjah, UAE \\ U14210513@sharjah.ac.ae; marab@sharjah.ae.ac; wzeiada@sharjah.ae.ac; momar@sharjah.ac.ae \\ ${ }^{2}$ Structural Engineering Department, Mansoura University \\ Al-Gomhoria Street, Mansoura, Egypt \\ ${ }^{3}$ Assistant Professor, College of Civil Engineering, King Saud University, Riyadh \\ 11421, Saudi Arabia. \\ alabduallah@ksu.edu.sa
}

\begin{abstract}
Soil improvement techniques of granular soils via Enzyme Induced Calcite Precipitation (EICP) have attracted an increasing attention as bio-based ground improvement technique. This technique uses biogeochemical reactions to precipitate calcium carbonate $\left(\mathrm{CaCO}_{3}\right)$. Calcium carbonate precipitate introduced into soil pores help bind soil particles and result in increased soil shear strength. The multiple-phase injection and percolation methods are currently adopted for EICP treatment to reach the desired soil shear strength. However, this method is rather complex and not feasible for practical applications. In this study, one-phase low-pH all-in-one solution (i.e. a mixture of urease enzyme, urea, $\mathrm{CaCl}_{2}$ and organic stabilizer) mixed with sand soil to enhance the soil shear strength has been proposed. Three different EICP cementing solutions have been investigating. A key factor that facilitated this approach is decrease the $\mathrm{pH}$ of the cementing solution to facilitate longer period and slower reaction of the precipitation of calcium. Unconfined compressive strength of 3.0 MPa was achieved by mixing cementing solution with soil without multiple treatment cycles.
\end{abstract}

Keywords: Urea hydrolysis, $\mathrm{CaCO}_{3}$, EICP, soil biocementation, soil improvement, bio-grouting.

\section{Introduction}

In order to enhance properties of shallow loose sand soil formations as foundation for lightly weighted structures like pavement, a wide range of techniques have been used. The majority of these ground improvement techniques use mechanical energy, replacement of soil and/or using binders, like cement or lime, to enhance soil shear strength. Nowadays, there a shift towards using new sustainable methods to improve soils without using cement due to the high emissions of carbon dioxide $\left(\mathrm{CO}_{2}\right)$ during cement production. Among other alternatives, calcite precipitation has been intensively investigated as a sustainable alternative for soil improvement. There are several techniques used to induce calcite precipitation, including urea hydrolysis, microbial induced calcite precipitation (MICP), Enzyme induced calcite precipitation (EICP) and microbial induced desaturation and precipitation (MIDP) [1].

MICP has been extensively investigated as biogeotechnical soil improvement technique (e.g., Van Paassen [2]; Whiffin et al. [3]). In MICP, ureolytic bacteria are introduced to the soil as part of the treatment solution as source of enzyme to catalyse the reaction. Both EICP and MICP treatment solutions include a calcium salt, usually in the form of calcium chloride $\left(\mathrm{CaCl}_{2}\right)$, and urea. Three-phase injection plan are usually adopted in MICP where the ureolytic bacterial in injected in the beginning into the soil pores. Followed by injection of solution of $\mathrm{CaCl}_{2}$, which work as a fixation agent for the bacterial cells to the soil particles [2]. Finally, a cementation fluid containing urea, calcium chloride, and in some cases additional nutrients and a pH stabilizer is injected [1]. More recently, Cheng et al. [4] proposed one-phase low-pH mixture of bacterial culture, urea, and $\mathrm{CaCl}_{2}$. The proposed acidic buffer provided lag period, which is a function of several parameters (i.e. $\mathrm{pH}$, biomass concentration, and urease activity), to allow even distribution within the soil pores and reduction of clogging in inlets pores [4]. Moreover, Cheng et al. [4] showed that the use of this one-phase approach reduced the production of the ammonia gas into the environment.

This research will focus on the use of urea hydrolysis reaction catalysed by urease enzyme derived from agricultural source, referred to as EICP. Unlike MICP, free urease enzyme derived from agricultural source catalyzes the hydrolysis of urea in the 
solution, which results in carbonate ion production. In the presence of calcium ions from any salt source, the carbonate ions precipitate as calcium carbonate as a result of increase in carbonate concentration beyond the level of super-saturation. Moreover, in EICP, there is no need to provide nutrients for bacterial activity Khodadadi et al. [5].

Hamadan and Kavazanjian [6] summarized EICP urea hydrolysis summery process in the following reaction steps: Ureolysis is catalyzed by the urease enzyme which hydrolyses urea $\left(\mathrm{CO}\left(\mathrm{NH}_{2}\right)_{2}\right)$ into carbon dioxide $\left(\mathrm{CO}_{2}\right)$ and ammonia $\left(\mathrm{NH}_{3}\right)$. In aqueous systems, ammonia may undergo speciation reactions forming ammonium $\left(\mathrm{NH}_{4}^{+}\right)$and thereby increasing the $\mathrm{pH}$ of the solution (creating conditions favourable to carbonate precipitation). The overall ureolytic reaction is

$$
\mathrm{CO}\left(\mathrm{NH}_{2}\right)_{2(a q)}+3 \mathrm{H}_{2} \mathrm{O}=\mathrm{CO}_{2(a q)}+2 \mathrm{NH}_{4(a q)}^{+}+2 \mathrm{OH}_{(a q)}
$$

Under the appropriate geochemical conditions and in the presence of a suitable divalent cation such as calcium, carbonate mineral precipitation can occur

$$
\mathrm{HCO}_{3}^{-}+\mathrm{HCO}_{3(a q)}^{-}+2 \mathrm{OH}_{(a q)}^{-}+\mathrm{Ca}_{(a q)}^{2+} \leftrightarrow \mathrm{CaCO}_{3}(s)+2 \mathrm{H}_{2} \mathrm{O}
$$

Combining the two above equations, the net urease-catalyzed precipitation reaction for calcium carbonate can be written as

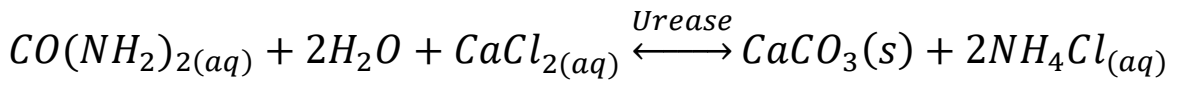

Since the EICP sand treatment depends on calcite precipitation, the effectiveness of a treatment technique is directly dependent on the spatial distribution of calcite. Of particular interest is the percentage of calcite and the distribution around soil particles.

\subsection{Prior Studies on Soil Improvement via EICP}

One of the challenges facing the practicality of the bio-treatment is the method of application. As mentioned earlier, multiple cycles of treatment have been reported to attain acceptable enhancement for sand soil. Several researchers have investigated several techniques to apply the EICP. Yasuhara et al. [7] mixed $0.33 \%$ of urease enzyme (with reported activity of $2950 \mathrm{U} / \mathrm{g}$ ) with Toyoura sand and then applied a 1:1 solution of urea to calcium chloride. In that study, three different equi-molar concentrations of urea and calcium chloride were introduced $0.5 \mathrm{M}, 1 \mathrm{M}$ and $1.5 \mathrm{M}$. After four cycles of treatment these investigators reported UCS results in the range from $0.75 \mathrm{MPa}$ to $1.6 \mathrm{MPa}$.

Almajed et al. [8] conducted a study to optimize the EICP solution to maximize the calcium carbonate precipitation. According to Almajed et al. [8], 37 different solutions of EICP were investigated inside 50-mL test tubes containing $20 \mathrm{~mL}$ of EICP solution without soil. The urea concentration was varied from 0.25 to $1.5 \mathrm{M}$, the ratio of $\mathrm{CaCl}_{2}$ to urea was varied from 1:1 to 1:1.75, and the enzyme concentration was varied from 1 to $6 \mathrm{~g} / \mathrm{L}$. The enzyme used in that study was jack beanextracted urease with a reported activity of 3,500 U/g. The EICP treatment solution was prepared by dissolving calcium chloride and urea into deionized water and then adding the free urease enzyme. Since the enzyme is considered to be the most expensive constituent in the cementing solution, it is important to optimize the urease enzyme in the solution. This study revealed preferred EICP solution based on high mass precipitation, high efficiency, and less enzyme consumption with $0.67 \mathrm{M}$ calcium chloride, $1 \mathrm{M}$ urea, and $3 \mathrm{~g} / \mathrm{L}$ urease enzyme. Important finding of this study is that the optimum ratio of the urea to calcium concentration was found to be 1:1.5. In the same study, Almajed et al. [8] used the optimized solution ( $0.67 \mathrm{M}$ calcium chloride, $1 \mathrm{M}$ urea, and $3 \mathrm{~g} / \mathrm{L}$ urease enzyme) to treat eight sand columns with two different methods of preparation (mix-and-compact and percolation methods). Four samples were prepared by percolation where they added only one pore volume of EICP solution from the top of the sample and then let the sample cure for 7 days with multiple cycles of treatment (maximum four cycles of treatment). The other four samples were treated by mix and compact, where 
dry sand was mixed with same volume of EICP solution used for the percolation test and with the same regime of percolation treatment after initial mix and compact. Almajed et al. [8] found out that samples treated with mix and compact did not have sufficient strength to measure the unconfined compressive strength. On the other hand, 1.2 MPa was achieved after four cycles and $99 \mathrm{kPa}$ after one cycle of treatment for samples treated with percolation method.

\section{Objectives}

Study was conducted to evaluate the possibility of using mix-and-compact technique to improve the soil without subsequent cycles of treatment. In this study, three EICP solutions were investigated with three levels of urea concentrations 1.0 M, 2.0 M and 3.0 M. The urea to calcium chloride ratio was fixed at 1:0.67 according to the findings of Almajed et al. [8]. The unconfined strength of the treated samples as well as the calcium carbonate precipitant concentration were investigated.

\section{Materials and Methods}

Graded silica sand (ASTM C778) $\left(\mathrm{e}_{\max }=0.95 ., \mathrm{e}_{\min }=0.66 ., \mathrm{D}_{50}=0.36, \mathrm{D} 10=0.2\right.$, Gs $=2.65$ ) was used throughout this study. The urease enzyme used in this study is jack bean-extracted urease with a reported activity of $=1500 \mathrm{U} / \mathrm{g}$ at $\mathrm{pH} 7$ and temperature $25{ }^{\circ} \mathrm{C}$ from (Fisher Chemical). High grade urea (99.9\%) from (Fisher Chemical) was used in this study along calcium carbonate powder with lab grade of (99\%) from (Fisher Chemical). Finally, organic stabilizer was used in the EICP solution (non-fat dry milk).

\subsection{Testing Program}

The experimental testing program included: (a) Unconfined Compressive Strength (UCS), (b) Scanning Electron Microscope (SEM) and (c) carbonate mineral content via acid digestion.

\subsection{EICP cementing solution}

Table 1 shows a summary of three EICP cementation solutions used with the constituents for each EICP solution. 1M solution is the solution that recommended by Almajed et al. [8]. The other two solutions are basically two and three times the concentration of each constituent of the $1 \mathrm{M}$ cementing solution. This cementing solution is proposed to examine of eliminating treatment cycles with EICP solution to reach comparable UCS.

Table 1: EICP cementing solutions used in this study.

\begin{tabular}{|l|c|c|c|c|}
\hline $\begin{array}{c}\text { EICP } \\
\text { solution }\end{array}$ & $\begin{array}{c}\text { Urea } \\
(\mathrm{M})\end{array}$ & Urea $: \mathrm{CaCl}_{2}$ & Enzyme (g/l) & $\begin{array}{c}\text { Organic } \\
\text { Stabilizer (g/l) }\end{array}$ \\
\hline $1 \mathrm{M}$ & 1 & $1: 0.67$ & 3 & 4 \\
\hline $2 \mathrm{M}$ & 2 & $1: 0.67$ & 6 & 8 \\
\hline $3 \mathrm{M}$ & 3 & $1: 0.67$ & 9 & 12 \\
\hline
\end{tabular}

The EICP cementing solution were prepared by adding all the constituents to deionized water without the enzyme. The solution was mixed carefully to make sure all the constituents are dissolved in the water. $\mathrm{The} \mathrm{pH}\left(\mathrm{pH}_{\text {intial }}\right)$ was measured before adding the enzyme to the solution. Afterwards, the free enzyme was added to the solution.

\subsection{Preparing treated sand columns}

Laboratory column tests were conducted in clear acrylic tubes that are $100 \mathrm{~mm}$ long and $50 \mathrm{~mm}$ inner diameter. The tubes were closed-off with a flexible cap and fastened with a hose clamp. The treated samples were prepared using mix-andcompact. To prepare columns using the mix-and-compact method, the amount of dry sand corresponding to a relative density of (89\%) was quickly mixed with $65 \mathrm{ml}$ of EICP solution (which is considered about one pore size of sand specimen). The 
sand/EICP mixture was then placed inside the tube in three lifts with firm compaction for each lift to reach a dry density of about $1613\left(\mathrm{~kg} / \mathrm{m}^{3}\right)$. The top of the first and second lifts was scratched prior to adding the next lift.

Three samples were prepared using each cementing solution and samples were lift to cure for 3, 7 and 14 days at room temperature. During the curing period, the top of the tube was closed by a stretch band to minimize evaporation of EICP After curing, the cementing solution was drained by gravity from the bottom by creating hole in the base of the tube. Later, specimens were flushed by adding one pore volume of deionized water to the top of the tube and allowing it to drain by gravity from the bottom. Tri-replicates were used for each treatment level. After curing, the specimen was carefully extracted from the tubes. The extracted samples were dried inside oven, at $105{ }^{\circ} \mathrm{C}$ for 24 hours, weighted every 8 hours to verify the dryness of the specimens. The UCS tests was performed in accordance with ASTM D 2166 [9]. The load was applied at a rate of $0.50 \%$ axial strain/minute.

After completing each test, the mass of calcium carbonate precipitated in each specimen was determined through acid digestion. In this method, each treated specimen was soaked into $4 \mathrm{M}$ hydrochloric acid $(\mathrm{HCl})$ until the effervescence was not observed anymore which means complete dissolving of the $\mathrm{CaCO}_{3}$. The samples are then washed carefully over filter paper and then oven dried $105{ }^{\circ} \mathrm{C}$ for 24 hours. The decrease in mass of the specimen before and after acid digestion was taken as the net mass of carbonate precipitation in the soil specimen. A small piece of cemented sand was chipped off each column and characterize using via SEM/EDX (Tescan VEGA XM variable pressure SEM/ Oxford Instruments X-Max 50 EDS detector). The specimens used for the SEM analysis were fixed with epoxy and then coated with a thin layer of gold for charge dissipation using Sputter Coating System (Quorum Technology Mini Sputter Coater, SC7620).

\section{Result and Discussion}

\subsection{Unconfined Compressive Strength (UCS) Results}

The stress strain curves of the treated sand specimens after 3 days of curing are presented in Fig. 1. It can be noted that from Fig. 1(a) the peak strength of the $1 \mathrm{M}$ treated specimens (three replicates) is about $170 \mathrm{kPa}, 226 \mathrm{kPa}$ and $262 \mathrm{kPa}$ with average of $219 \mathrm{kPa}$. It is important to note here that compressive strength was completely lost after peak (after failure) and residual compressive strength was almost zero.

Fig.1(b) shows the UCS stress strain curve results in case of using $2 \mathrm{M}$ cementing solution. The results show a peak compressive strength for the three replicates of about $292 \mathrm{kPa}, 320 \mathrm{kPa}$ and $330 \mathrm{Kpa}$ with an average of about $314 \mathrm{kPa}$. In this case, an increase of UCS of about $59 \%$ was attained in case of $2 \mathrm{M}$ cementing solution compared to $1 \mathrm{M}$ cementing solution.

Finally, Fig. 1(c) shows the results for case of the three replicates sand samples treated with 3M EICP solution. In this case, an average compressive strength of $504 \mathrm{kPa}$ was achieved for the three replicates with an increase of about $150 \%$ compared to the $1 \mathrm{M}$ treated sand specimens. Also, it is important to note the variability in peak compressive strength in case of $3 \mathrm{M}$ treated samples is much lower than in case of $1 \mathrm{M}$ and $2 \mathrm{M}$ treated specimens. Moreover, the $3 \mathrm{M}$ treated samples have showed ductility after peak strength and gradual failure was noticed compared to sudden failure observed for $1 \mathrm{M}$ and $2 \mathrm{M}$ treated samples. Failure in this case was around $1 \%$ strain compared to $0.6 \%$ and $0.5 \%$ for the $2 \mathrm{M}$ and $1 \mathrm{M}$ treated samples respectively.

Fig. 2 shows the failure shape for the two samples treated with $3 \mathrm{M}$ solution after 3 days of curing time. The failure in Fig. 2(a) suggest zone of weaker cementation compared to the rest of the specimen, while the failure shown for the specimen\# 2 in Fig. 2 (b) suggests tensile failure mode.

\subsection{SEM Results}

The samples taken for SEM/EDS were fixed with epoxy fixation and then the specimen surface was polished. Afterwards the sample was coated with gold. SEM picture shown in Fig. 3(a) shows the sand particle with the calcium carbonate precipitation at soil surface and at soil/soil contact points. The SEM picture then was analysed using element mapping technique to show the spatial distribution of chemical elements. The soil particles are defined by the silicon as shown in Fig. 3(c). Fig. 3(d) shows the calcium element spatial distribution and confirms the calcite distribution around sand particles with calcium carbonate concentration at particle/particle contacts. 


\subsection{Initial pH}

The initial $\mathrm{pH}$ level was measured by $\mathrm{pH}$ meter from (Sper Scientific) two times. The $\mathrm{pH}$ is measured after mixing the EICP cementing constituents and before adding the enzyme and immediately after adding the enzyme. The results of the $\mathrm{pH}$ measurements are shown in Table 2. The results show that for the $1 \mathrm{M}$ the $\mathrm{pH}$ is 5.69 and decreases with the increase of the urea concentration. This decrease of the $\mathrm{pH}$ may result in lag of carbonate precipitation and uniform distribution of carbonate precipitation in the soil matrix as shown by Cheng et al. [4].

Table 2: pH level at different concentrations of EICP cementing solution.

\begin{tabular}{|c|c|c|}
\hline EICP cementing solution & $\mathrm{pH}_{\text {intial }}$ & EICP solution $\mathrm{pH}$ \\
\hline $1 \mathrm{M}$ & 5.69 & 7.05 \\
\hline $2 \mathrm{M}$ & 4.94 & 6.9 \\
\hline $3 \mathrm{M}$ & 4.46 & 6.47 \\
\hline
\end{tabular}
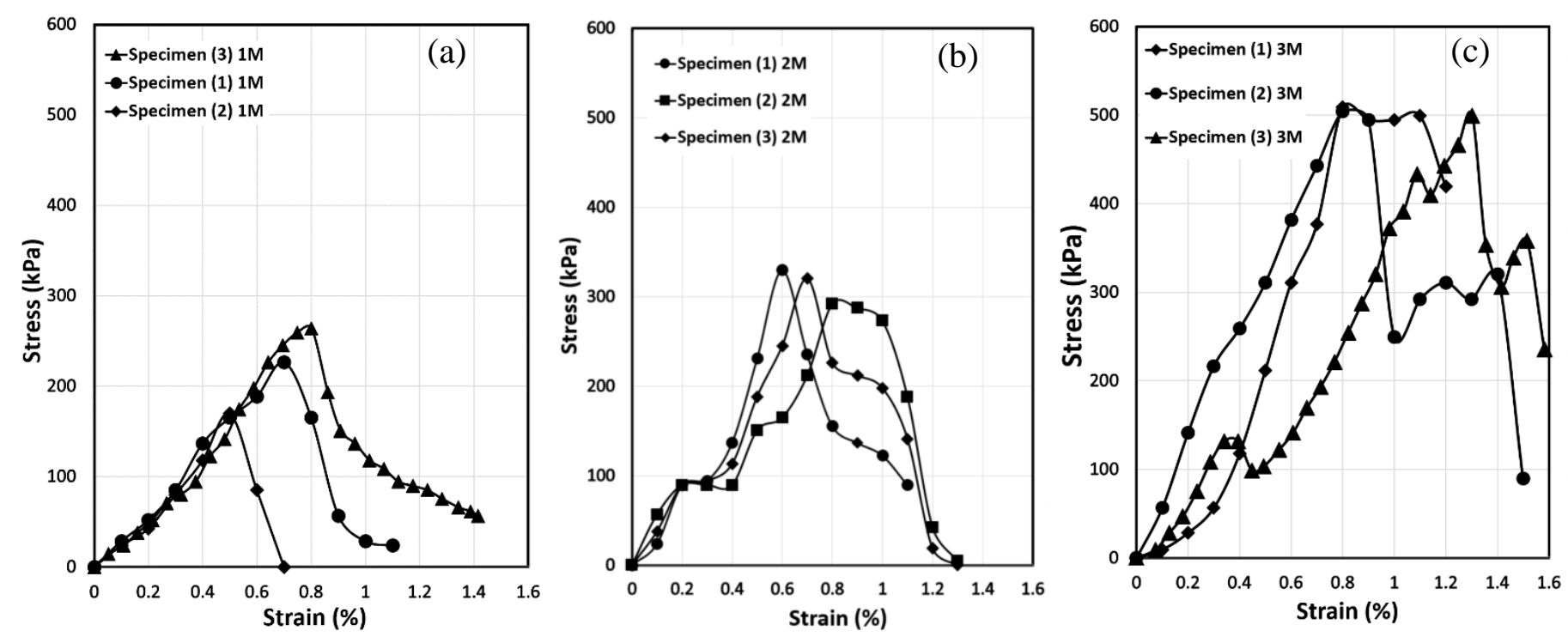

Fig. 1: UC test results after 3 days of curing for treated sand with: (a) 1M EICP cementing solution; (b) 2M EICP cementing solution;

(c) 3M EICP cementing solution. 


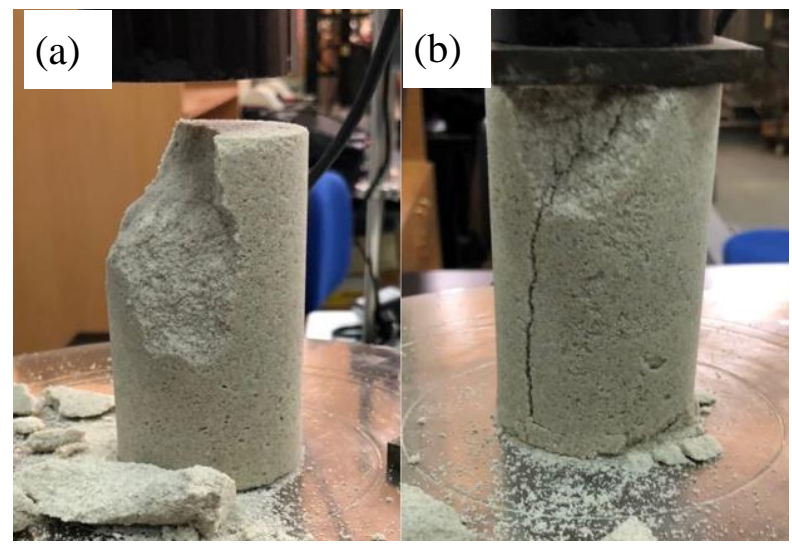

Fig. 2: Failure shapes for 3M treatment specimens (a) Specimen \#1; (b) Specimen \#2.
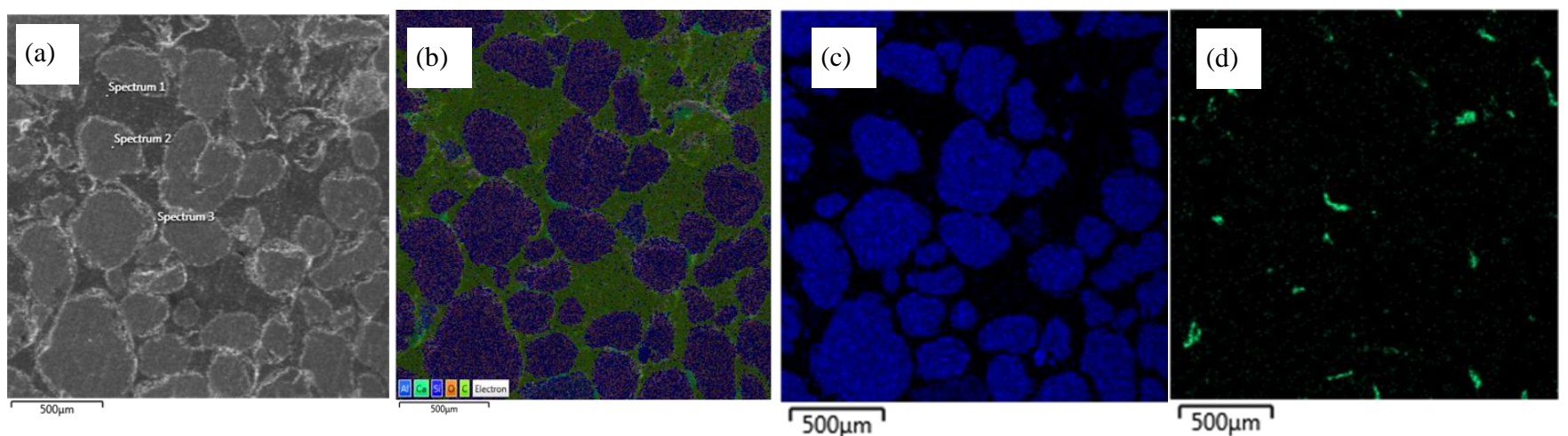

Fig. 3: (a) SEM Picture of treated specimen with 1M EICP after 4 days of treatment, (b) EDS element mapping of the chemical components; (c) Silicon spatial distribution; (d) Calcium spatial Distribution.

\subsection{Effect of Curing Time}

To investigate the effect of curing time for 3M EICP treated specimens, samples were left to cure for 3, 7 and 14 days at room temperature after mixing the soil with EICP solution. The samples then were flushed with deionized water and tested. Fig. 4(a) shows the stress strain curve for $3 \mathrm{M}$ treated specimens after 3, 7 and 14 days of curing. The $3 \mathrm{M}$ treated specimen left to cure for 14 days showed a peak strength of about $3.0 \mathrm{MPa}$ with an increase of about $500 \%$ compared to samples left to cure only 3 days. Fig. 4(b) shows the peak compressive strength of $3 \mathrm{M}$ treated samples versus curing time with linear increase of UCS. This indicates that the 3 days were not enough for the compressive strength of treated soil to be fully developed. This is may be attributed to that the reaction was not concluded in three days and the increase in curing time allowed for an increase in calcium carbonate precipitation. This prolonged reaction time can be attributed to the low $\mathrm{pH}_{\text {intial }}$ of the cementing solution. This agrees with the findings of Cheng et al. [4]. 

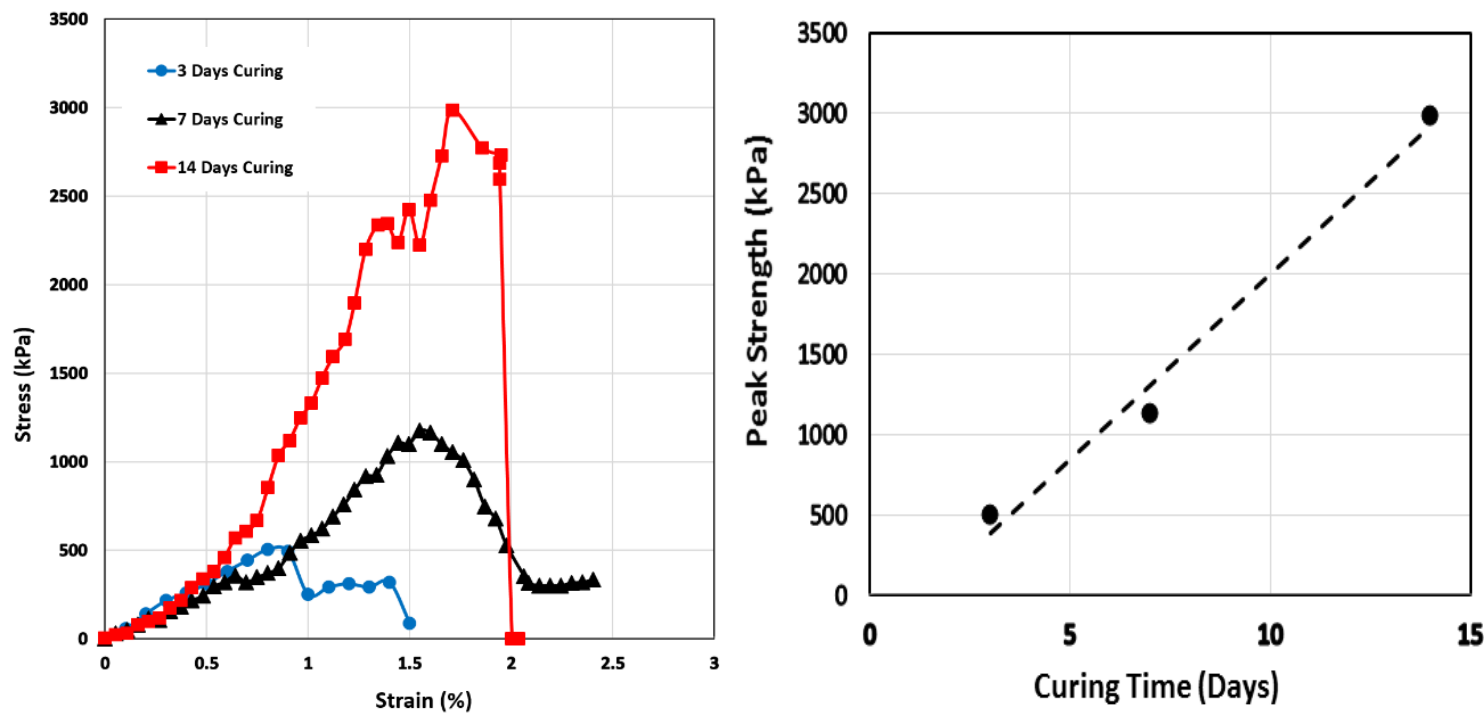

Fig. 4: (a) UC test of 3M treated Graded ASTM sand for 3-7 and14-days curing; (b) Relationship between Peak Strength and curing time.

\subsection{Calcium carbonate content}

Fig. 5 shows the relationship between peak UCS and the calcium carbonate content of all the specimens tested in this testing program. The relationship is bi-linear with initial mild increase of UCS with the increase of the carbonate content as illustrated in Fig. 5. The UCS increased then dramatically when the calcium carbonate precipitation exceeded about $3.5 \%$ of the total dry weight. This agrees with Whiffin et al [3] who found a threshold of $\mathrm{CaCO}_{3}$ of about $3.5 \%$ after which a significant increase was achieved in compressive strength using MICP treated sands.

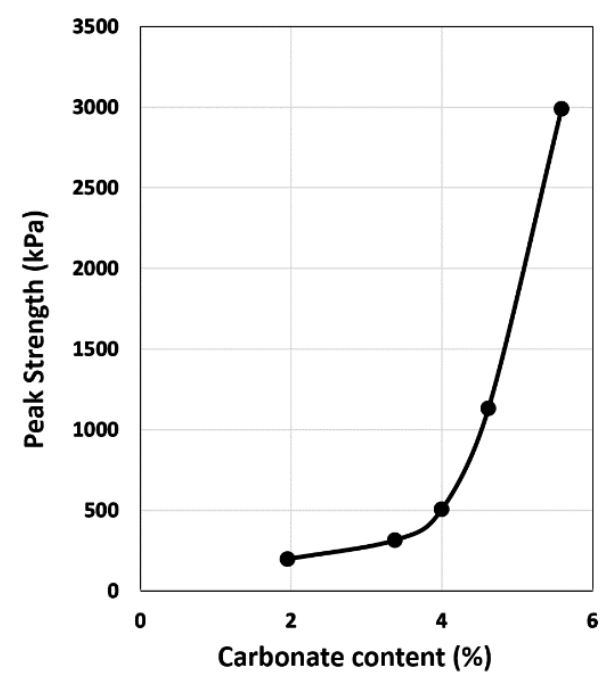

Fig. 5: Relationship between strength and carbonate content. 


\section{Conclusions}

This paper investigated the use of EICP bio-cementation method using of one phase of treatment without cycles of treatment. Three different EICP solutions were investigated. The EICP solution with highest concentration has led to lower $\mathrm{pH}$ that resulted in a lag in the cementation process. The following general conclusions can be driven from the curreht Thedting sand with EICP solution can be done with one cycle of EICP by increasing urea concentration which resulted in decrease in the $\mathrm{pH}$. This may have resulted in lag time for the reaction, which result in higher carbonate content and higher compressive strength. However, this conclusion need further investigation in future studies.

2- The sand treated with 1M EICP cementing solution shows higher variability in the UCS results which may suggest non-uniform distribution of calcium precipitation. The specimens treated with higher concentration of EICP solution have showed relatively lower variability in UCS results which may suggest more uniform distribution of the carbonate precipitation.

3- The UCS showed a general trend of increase with the increase in the $\mathrm{CaCO}_{3}$ content with a bi-linear behaviour and an inflation point of about $3.5 \%$ of calcium carbonate content.

4- SEM analysis has confirmed that the calcium carbonate precipitation at sand/sand particle contact points.

5- A compressive strength of about 3.0 MPa was achieved after 14 days of curing with soil treated with 3M EICP cementing solution. This compressive strength was achieved with one shot treatment without multiple cycles of treatments.

\section{References}

[1] J. DeJong, K. Soga, E. Kavazanjian, S. Burns, L. Van Paassen, A. Al Qabany, et al., "Biogeochemical processes and geotechnical applications: progress, opportunities and challenges," 2013.

[2] L. A. Van Paassen, "Biogrout, ground improvement by microbial induced carbonate precipitation," 2009.

[3] V. S. Whiffin, L. A. van Paassen, and M. P. Harkes, "Microbial carbonate precipitation as a soil improvement technique," Geomicrobiology Journal, vol. 24, pp. 417-423, 2007.

[4] L. Cheng, M. A. Shahin, and J. Chu, "Soil bio-cementation using a new one-phase low-pH injection method," Acta Geotechnica, pp. 1-12, 2018.

[5] T. Hamed Khodadadi, E. Kavazanjian, L. Van Paassen, and J. DeJong, "Bio-grout materials: A review," in Grouting, 2017, pp. 1-12.

[6] N. Hamdan and E. Kavazanjian Jr, "Enzyme-induced carbonate mineral precipitation for fugitive dust control," Géotechnique, vol. 66, pp. 546-555, 2016.

[7] H. Yasuhara, D. Neupane, K. Hayashi, and M. Okamura, "Experiments and predictions of physical properties of sand cemented by enzymatically-induced carbonate precipitation," Soils and Foundations, vol. 52, pp. 539-549, 2012.

[8] A. Almajed, H. Khodadadi Tirkolaei, and E. Kavazanjian Jr, "Baseline Investigation on Enzyme-Induced Calcium Carbonate Precipitation," Journal of Geotechnical and Geoenvironmental Engineering, vol. 144, pp. 04018081, 2018.

[9] American Society for Testing and Materials (ASTM), "Standard Test Method for Unconfined Compressive Strength of Cohesive Soil," Designation D, pp. 2166-06, 2013

[10] M. P. Harkes, L. A. Van Paassen, J. L. Booster, V. S. Whiffin, and M. C. van Loosdrecht, "Fixation and distribution of bacterial activity in sand to induce carbonate precipitation for ground reinforcement," Ecological Engineering, vol. 36, pp. 112-117, 2010. 